\title{
THE DUALITY OF TECHNOLOGY: RETHINKING THE CONCEPT OF TECHNOLOGY IN ORGANIZATIONS
}

\author{
Wanda J. Or.':kowski \\ January 1991
}

CISR WP No. 219

Sloan WP No. 3141-91

CCSTR \#105

-1991 W.J. Orlikowski

Forthcoming in Organization Science.

Center for Information Systems Research

Sloan School of Management

Massachusetts Institute of Technology 


\title{
THE DUALITY OF TECHNOLOGY:
}

\section{Rethinking the Concept of Technology in Organizations}

\begin{abstract}
This paper develops a new theoretical model with which to examine the interaction between technology and organizations. Early research studies assumed technology to be an objective, external force that would have deterministic impacts on organizational properties such as structure. Later researchers focused on the human aspect of technology, seeing it as the outcome of strategic choice and social action. This paper suggests that either view is incomplete, and proposes a reconceptualization of technology that takes both perspectives into account. A theoretical model-the structurational model of technology--is built on the basis of this new conceptualization, and its workings explored through discussion of a field study of information technology. The paper suggests that the reformulation of the technology concept and the structurational model of technology allow a deeper and more dialectical understanding of the interaction between technology and organizations. This understanding provides insight into the limits and opportunities of human choice, technology development and use, and organizational design. Implications for future research of the new concept of technology and structurational model of technology are discussed.
\end{abstract}


Technology has always been a central variable in organizational theory, informing research and practice. Despite years of investigative effort there is little agreement on the definition and measurement of technology, and no compelling evidence on the precise role of technology in organizational affairs. I will argue that the divergent definitions and opposing perspectives associated with technological research have limited our understanding of how technology interacts with organizations, and that these incompatibilities cannot be resolved by mutual concession. What is needed is a reconstruction of the concept of technology, which fundamentally re-examines our current notions of technology and its role in organizations.

In this paper, I undertake such a reconstruction and present a view of technology that draws on Giddens' $[1976,1979,1984]$ theory of structuration. My re-examination leads to a model for analyzing the nature and role of technology in organizations, which I term the structurational model of technology. Before proceeding to the premises and components of this model, prior views of technology are reviewed to serve as background and motivation for the altemative proposed here.

\section{RETHINKING PRIOR CONCEPTUALIZATIONS OF TECHNOLOGY}

Prior conceptualizations of technology have each focused selectively on some aspects of technology, at the expense of others, with the result that the current state of knowledge about technology in organizations is ambiguous and conflicting [Attewell and F lle 1986; Barley 1990; Davis and Taylor 1986; Hartmann et al. 1986; Scott 1981]. Two important aspects of the technology concept are scope--what is defined as comprising technology, and role--how is the interaction between technology and organizations defined. Both these aspects inform prior technological research, where they have been specified and used discrepantly.

\section{Differences in Scope}

Two views on the scope of technology have pervaded (and shaped) studies of technology, reflecting the different claims to generalizability that researchers have intended with their work. The one set of studies has focused on technology as "hardware," that is, the equipment, machines, and instruments that humans use in productive activities, whether industrial or informational devices [Barley 1986; Blau et al. 1976; Bjørn-Andersen, Eason and Robey 1986; Davis 1989; Hickson et al. 1969; Lucas 1975; Noble 1984; Robey 1981; Shaiken 1985; Woodward 1958; Zuboff 1988]. The range of hardware across industries and organizations however, has led to multiple, contextspecific definitions of technology, which have inhibited comparisons across studies and settings. For example, Woodward's [1958] categorization of technology as industrial production techniques is limited to manufacturing firms. Alternatively, this approach has also resulted in the use of broad definitions of technology which, having to accommodate a wide range of machinery, become so abstract as to have limited discriminatory or informational value. For example, Blau et al.'s [1976] 
definition of technology, deployed in the factory and the office, is given as "the substitution of equipment for human labor" [1976:21].

In the "hardware" view, technology is a meaningful variable only in those organizations that employ machinery in their productive activities. This restriction prompted researchers to try and generalize the scope of the technology variable so as to encompass organizations such as service firms and educational institutions. The technology concept was thus extended to "social technologies," thereby including the generic tasks, techniques, and knowledge utilized when humans engage in any productive activities [Eveland 1986; Perrow 1967; Thompson 1967]. For example, Perrow [1967] sees organizations as places where raw materials are transformed, thus defining what is done to raw materials and how it is done, as the technology of organizations, while Thompson [1967] characterizes the work flow of different organizations in terms of longlinked, mediating, and intensive technologies.

While useful, in that it allows technology to be a meaningful variable in all organizations, and it recognizes that there is more to technology than just the hardware, this generic approach to technology creates boundary and measurement ambiguity [Mintzberg 1979:250]. It also overlooks valuable information about the mediation of human action by machines. That is, even as we gain in generality, we have ist the ability to ask questions about how artifacts interact with human agents. By aggregating task, technique, knowledge, and tools into a single construct - technology interaction among these constituting components and with humans is ignored. For example, we cannot examine how different assumptions, knowledge, and techniques can be embedded in different kinds of artifacts or practices, and how these will have differential consequences for human action and cognition. Nor can we examine how the rules and procedures structured into a machine are differentially appropriated, changed, or ignored by the agents executing work [Perrow 1983; Suchman and Wynn 1984; Wynne 1988].

\section{Differences in Role}

Three streams of technology research can be distinguished by their definitions of the role played by technology in organizations, reflecting the philosophical opposition between subjective and objective realms that has dominated the social sciences [Bemstein 1978; Burrell and Morgan 1979; Giddens 1979]. The early work assumed technology to be an objective, external force that would have (relatively) deterministic impacts on organizational properties such as structure. In contrast, a later group of researchers focused on the human action aspect of technology, seeing it more as a product of shared interpretations or interventions. The third, and more recent work on technology, has reverted to a "soft" determinism where technology is posited as an external force having impacts, but where these impacts are moderated by human actors and organizational contexts. 


\section{The "Technological Imperative" Model}

In this body of work, studies of technology [Aldrich 1972; Blau et al. 1976; Hickson et al. 1969; Perrow 1967; Shepard 1977; Woodward 1958] and information technology [Carter 1984; Davis 1989; Foster and Flynn 1984; Hiltz and Johnson 1990; Leavitt and Whistler 1958; Pfeffer and Leblebici 1977; Siegel et al. 1986] examine the impacts of technology on organizational dimensions such as structure, size, performance, and centralization/decentralization, as well as individual level dimensions such as job satisfaction, task complexity, skill levels, communication effectiveness, and productivity. The premise is that the technology as well as the organizational and individual variables can be measured and predicted (see Figure 1).

Such research treats technology as an independent influence on human behavior or organizational properties, that exerts unidirectional, causal influences over humans and organizations, similar to those operating in nature [Giddens 1984:207]. Some of this research allows for the influence of technology to be moderated by contextual variables, proposing a contingency model of technology's effects [e.g., Jarvenpaa 1989; Lucas 1975]. While providing insight into the often determining aspects of technology, this body of research largely ignores the action of humans in developing, appropriating, and changing technology. As a consequence, this perspective furnishes an incomplete account of technology and its interaction with organizations.

\section{Organizational Dimensions}

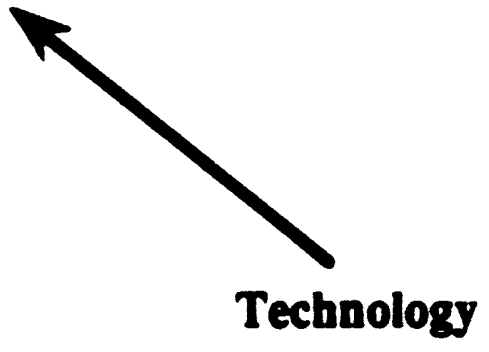

Figure 1: Technological Imperative Model 


\section{The "Strategic Choice" Model}

This perspective suggests that technology is not an external object, but a product of ongoing human action, design, and appropriation. Three research foci within this perspective are discemable. One stream focuses on how a particular technology is physically constructed through the social interactions and political choices of human actors. Technology is here understood to be a dependent variable, contingent on other forces in the organization, most notably powerful human actors (see Figure 2). This perspective does not accept that technology is given or immutable, focusing attention instead on the manner in which technology is influenced by the context and strategies of technology decision makers and users [Child 1972; Davis and Taylor 1986; Kling and Iacono 1984; Markus 1983; Perrow 1983; Trist et al. 1963; Zuboff 1988].

Particularly relevant here are socio-technical studies, which are premised on the belief that outcomes such as job satisfaction and productivity of workers can be manipulated by jointly "optimizing" the social and technical factors of jobs [Davis and Taylor 1986; Trist et al. 1963]. A similar premise runs through the socio-technical research in information technology [Bostrom and Heinem 1977; Mumford 1981] and the work of Zuboff [1988], which calls for a re-examination and restructuring of organizations around the potential of information technology. Zuboff suggests that because information technology can be designed with different intentions (to "automate" or "informate" work), it will have different implications for workers (controlling and deskilling or empoweri. ${ }_{0}$ and upskilling, respectively).

\section{Organizational Context}

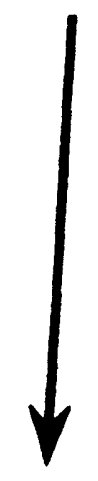

Technology

\section{Decision-Makers}

Figure 2: Strategic Choice Model 
These analyses, however, rely too heavily on the capability of human agents. The presumption is made that once technology is designed to embody the "appropriate" (optimizing or informating) objectives and once managers are committed to this "appropriate" strategy, more rewarding workplaces, more fluid organizations, a new division of labor, and better performance will result. But, as many of the case studies in Zuboff [1988] reveal, how a technology is deployed and appropriated depends on social and economic forces beyond managerial intent [Powell 1987; Sabel 1982; Shaiken 1985], which may thwart any intended reconstruction of jobs and technology. Some of these forces include: institutional properties of the organization, micropolitics of the workplace, features of the environment, and unintended consequences of organizational change. Such forces may account for the mixed success that socio-technical interventions have had in a range of organizations [Kelly 1978; Pasmore et al. 1982].

The second stream examines how shared interpretations around a certain technology arise and affect the development of and interaction with that technology. Empirical studies adopting this social constructionist view of technology have been done by sociologists of technology [Bijker 1987; Bijker, Hughes and Pinch 1987; Collins 1987; Pinch and Bijker 1984, 1987; Woolgar 1985; Wynne 1988], and information technology researchers [Boland and Day 1982; Hirschheim, Klein and Newman 1987; Klein and Hirschheim 1983; Newman and Rosenberg 1985]. While usefully demonstrating how meanings around a technology arise and are sustained, this body of reseurch tends to downplay the material and structural aspects of interaction with technology.

The final research stream in this tradition is represented by Marxist accounts of technology such as those of Braverman [1974], Cooley [1980], Edwards [1979], Noble [1984], and Perrolle [1986]. While carefully outlining the manner in which technology is devised and deployed to further the political and economic interests of powerful actors (the social construction of technology at the point of initiation), these studies do not adequately deal with human agency in the workplace (the social construction of technology at the point of use). They consequently fail to account for the diverse ways in which a technology is appropriated and utilized by workers, and the nonuniform manner in which it structures individual and organizational action [Burawoy 1979; Powell 1987]. The limitation here is the selectivity with which the notion of human agency is applied, where only managers or technology designers have the authority and means to shape the technology. Human agents such as workers using the technology are portrayed as relatively powerless, and their actions and cognitions as determined by the technology. Yet, worker action may well change how technology is interpreted and operated, and hence the implications for organizations [Burawoy 1984; Jönsson and Grönlund 1988; Perrow 1983; Wynne 1988]. As Mohrman and Lawler [1984:136] point out: "Because technologies are socially constructed, they can be reconstructed as well. ... The technology itself can be changed by those using it." 


\section{Model of Technoblogy as Trigger of Structural Change}

A third perspective on the relationship between technology and structure is provided by Barley [1986, 1990], and involves portraying technology as an intervention into the relationship between human agents and organizational structure, which potentially changes it (see Figure 3). Barley [1986] employed a longitudinal field study to examine the introduction of similar radiographic technology into different organizations. Within each organization, he found that the technology triggered a change in departmental structure by altering institutionalized roles and patterns of interaction. By comparing two organizations and determining that they responded differently to the implementation of a similar technology, Barley [1986:107] effectively demonstrated that: "Technologies do influence organizational structures in orderly ways, but their influence depends on the specific historical process in which they are embedded."

Within his frame of reference Barley posits a role for technology, not as material cause, but as a material trigger, occasioning certain social dynamics that lead to anticipated and unanticipated structuring consequences (such as increased decentralization in his study). Technology is understood as a social object whose meaning is defined by the context of use, while its physical form and function remain fixed across time and contexts of use. While Barley asserts that some f tures of the technology are socially constructed, he does not allow for the physical modification of technology during use. Given a technology such as CT scanners--with relatively fixed and standardized functions and features--such a view may be appropriate. It is, however, not generally appropriate, and is particularly inadequate in the case of information technologies. While technologies may appear to have objective forms and functions at one point, these can and do vary by different users, by different contexts of use, and by the same users over time.

\section{Reviewing the Technology Literature}

The above discussion has been a brief and somewhat critical examination of extant research into the scope and role of technology in organizations. This examination is not original, as recent discussions in the organizational literature have similarly critiqued this work [Attewell and Rule 1984; Davis and Taylor 1986; Hodson and Parker 1988; Markus and Robey 1988; Perrow 1983; Powell 1987; Sabel 1982]. However, while researchers have concentrated on deconstruction to identify the limitations imposed by overly deterministic or unduly voluntaristic perspectives, they have not engaged in the equally important task of reconstruction. What is still lacking is a new conceptualization of technology and its relationship with organizations that will allow us to move beyond critique to an alternative conceptual basis from which to conduct future research. 
Organizational Structure at T1 (without technology)

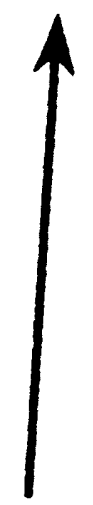

Human Agents
Organizational Structure at T2 (with technology)
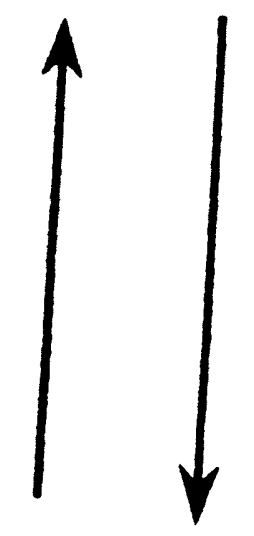

Human Agents

time

Figure 3: Barley's [1986] Model of Technology-triggered Structural Change

In this paper, I employ the tenets of structuration theory to reconstruct the concept of technology and to propose a model for investigating the relationship between technology and organizations. In defining my concept of technology, I restrict its scope to material artifacts (various configurations of hardware and software). I wish to sustain a distinction--at least theoretically--between the material nature of technology and the human activities that design or use those artifacts. This definition is consistent with the view that overloading the technology concept is unnecessarily limiting, but it should not be understood as an exclusive focus on technology as a physical object. In contrast, the analytic decoupling of artifacts from human action allows me to conceptualize material artifacts as the outcome of coordinated human action and hence as inherently social. It also facilitates my framing of the role of technology in terms of a mutual interaction between human agents and technology, and hence as being socially constructed and structural. 
My proposal for a structurational model of technology makes no claims as to completeness or perfection, and is presented as another in the stream of thinking about the technology phenomenon. It too, inevitably, is limited by its author's beliefs and interests. I submit however, that the reconceptualization, while bounded, overcomes certain dualisms and abstractions that are inherent in prior perspectives, and sensitizes us to the dialectical interplay of technology and organizations.

\section{A STRUCTURATIONAL MODEL OF TECHNOLOGY}

Recent work in social theory [Giddens 1976, 1984] and philosophy of science [Bernstein 1978; Bhaskar 1979] has challenged the long-standing opposition in the social sciences between subjective and objective dimensions in social reality, and proposes an alternative meta-theory which incorporates both dimensions. Giddens' theory of structuration $[1979,1984]$ is one such alternative, and a number of organizational researchers have adopted and used the theory in their analyses of organizational processes [Barley 1986; Manning 1982; Pettigrew 1985; Ranson, Hinings and Greenwood 1980; Riley 1983; Roberts and Scapens 1985; Smith 1983; Spybey 1984; Willmott 1987]. For these researchers, structuration offers a solution to the dilemma of choosing between subjective and objective conceptions of organizations, and allows them to embrace both [Dow 1988; Poole and Van de Ven 1989; Willmott 1981].

\section{The Theory of Structuration}

Structuration is posited as a social process that involves the reciprocal interaction of human actors and structural features of organizations. The theory of structuration recognizes that human actions are enabled and constrained by structures, yet that these structures are the result of previous actions. In Giddens' framework, structure is understood paradigmatically, that is, as a generic concept that is only manifested in the structural properties of social systems [Giddens 1979:64-65]. Structural properties consist of the rules and resources that human agents use in their everyday interaction. These rules and resources mediate human action, while at the same time they are reaffirmed through being used by human actors.

In this theory, the role of human actors in reaffirming structural properties is highlighted so as to avoid reification. The recognition that actors are knowledgeable and reflexive is a central premise. Giddens notes [1984:22]: "All social actors, all human beings are highly 'learned' in respect of knowledge which they possess and apply, in the production and reproduction of day-to-day social encounters." Giddens distinguishes between discursive and practical knowledge, where the former refers to knowledge the actors are able to articulate (what is said), and the latter refers to tacit knowledge, which actors are able to draw on in action but are unable to express (what is simply done). Reflexivity refers to the capacity of humans to routinely observe and understand what they 
are doing while they are doing it. It is not merely self-consciousness, but includes the continuous monitoring of physical and social contexts, and activities (their own and others) [Giddens 1984:5]. Actors' knowledge and reflexivity, however, is always bounded to some extent by the situated nature of action, the difficulty of articulating tacit knowledge, unconscious sources of motivation, and unintended consequences of action [Giddens 1979:144].

Through the regular action of knowledgeable and reflexive actors, patterns of interactions become established as standardized practices in organizations, e.g., ways of manufacturing a product, coordinating a meeting, or evaluating an employee. Over time, habitual use of such practices eventually become institutionalized, forming the structural properties of organizations. These structural or institutionalized properties (structure) are drawn on by humans in their ongoing interactions (agency), even as such use, in turn, reinforces the institutionalized properties. In this formulation--known as the duality of structure--Giddens overcomes the dualism between objective, structural features of organizations and subjective, knowledgeable action of human agents.

When humans act in organizations, they create and recreate three fundamental elements of social interaction [Giddens 1976:104]: meaning, power, and norms. While these elements are highly interdependent and not separable in practice, for analytical purposes we can treat them as distinct, examining each from the perspective of human agency and institutionalized properties.

- From an agency point of view, human interaction involves the constitution and communication of meaning. This is achieved via interpretive schemes or stocks of knowledge that humans draw on in their ongoing interaction with the world, which "... form the core of mutual knowledge whereby an accountable universe of meaning is sustained through and in processes of interaction" [Giddens 1979:83]. The interpretive schemes, however, do more than merely enable shared meanings and hence mediate communication. From the perspective of institutionalized properties, interpretive schemes represent organizational structures of signification, which represent the organizational rules that inform and define interaction. Interpretive schemes are also reinforced or changed through social interaction, as the organizational rules are reaffirmed or challenged through their use by human agents. Thus, in any interaction, shared knowledge is not merely part of the background, but is an integral part of the social encounter, in part organizing it, and in part being shaped by the interaction itself.

- From an agency perspective, power enters into human interaction through providing organizational capabilities for humans to accomplish outcomes. Power is here understood as "transformative capacity," the power of human action to transform the social and material world [Roberts and Scapens 1985:449]. Its use in organizations is mediated via the organizational resources that participants bring to, and mobilize within, interaction [Giddens 1979:92-93]. Two kinds of resources are recognized, authoritative (extending over persons) 
and allocative (extending over objects or material phenomena). While these facilities are the means through which power is exercised, from the perspective of institutional properties they constitute organizational structures of domination, which reflect the fact that all social systems are marked by an asymmetry of authoritative and allocative resources. However, there always remains the potential for agents to act to change a particular structure of domination, a potentiality referted to as the dialectic of control by Giddens [1984:16]: “... all forms of dependence offer some resources whereby those who are subordinate can influence the activities of their superiors." When a given asymmetry of resources is drawn on by human actors in interaction, the existing structure of domination is reaffirmed. It is only when the existing asymmetry of resources is changed-either through being explicitly altered or through being gradually and imperceptibly shifted--that the existing structure of domination may be modified or undermined.

- From an agency perspective, norms are organizational conventions or rules governing legitimate or "appropriate" conduct. Interaction in organizations does not occur blindly but is guided by the application of normative sanctions, expressed through the cultural norms prevailing in an organization. From the perspective of institutional properties, however, norms constitute organizational structures of legitimation, whereby a moral order within an organization is articulated and sustained through rituals, socialization practices, and tradition.

Giddens does not explicitly address the issue of technology in his structuration paradigm, and while structuration theory has been employed to study technology-induced organizational change [Barley 1986], and applied to the use of group decision support systems [Poole and DeSanctis 1989, 1990] and computer conferencing systems [Robey, Vaverek and Saunders 1989], no attempt has been made to use structuration theory to reconceptualize the notion of technology, and to reformulate the relationship between technology and organizations. In suggesting that we try and understand technology from the point of view of structuration, I propose that it be considered as one kind of structural property of organizations developing and/or using technology. That is, technology embodies and hence is an instantiation of some of the rules and resources constituting the structure of an organization. The details of a structurational model of technology are explicated in the following section, and the model is then illustrated by drawing on empirical work.

\section{Premises of a Structurational Model of Technology}

Technology is created and changed by human action, yet it is also used by humans to accomplish some action. This recursive notion of technology--which I call the duality of technology--is the first of the premises I elaborate below. The second, a corollary of the first, is that technology is interpretively flexible, hence that the interaction of technology and organizations is a function of the different actors and socio-historical contexts implicated in its development and use. 


\section{(i) The Duality of Technology}

The duality of technology identifies prior views of technology--as either objective force or as socially constructed product--as a false dichotomy. Technology is the product of human action, while it also assumes structural properties. That is, technology is physically constructed by actors working in a given social context, and technology is socially constructed by actors through the different meanings they attach to it and the various features they emphasize and use. However, it is also the case that once developed and deployed, technology tends to become reified and institutionalized, losing its connection with the human agents that constructed it or gave it meaning, and it appears to be part of the objective, structural properties of the organization.

Agency and structure are not independent. It is the ongoing action of human agents in habitually drawing on a technology that objectifies and institutionalizes it. Thus, if agents changed the technology--physically or interpretively--every time they used it, it would not assume the stability and taken-for-grantedness that is necessary for institutionalization. But such a constantly evolving interaction with technology would undermine many of the advantages that accrue from using technology to accomplish work. We do not need to physically or socially reconstruct the telephone, elevator, or typewriter every time we use it. However, there clearly are occasions where continued unreflective use of a technology is inappropriate or ineffective.

Wynne [1988:159], for example, describes the case of a British water-transfer tunnel designed in the seventies to serve the huge increase in water demand expected as a result of the projected industrial and residential growth of Lancashire. At the time of the design and implementation of the technology, it was assumed that the scheme would pump continually and at full capacity. However, a decade later it turned out that these social assumptions had been incorrect; Lancashire was economically depressed and water demand had not increased. As a result, the scheme was only used intermittently and lay stagnant for periods of several weeks. Such operation of the scheme allowed the formation of a large void in the tunnel, which eventually caused a major methane explosion in the tunnel with significant loss of life. The operation of the technology depended in this case on the once-relevant, but now-obsolete and forgotten assumptions about the socio-economic growth of the area. Having been designed and built into the technology, these assumptions served às conditions for the "normal" operation of the technology. That the conditions were no longer applicable to current operational circumstances was no longer known to users, and unavailable for reflection by them or the technology sponsors and developers who were long gone.

As was indicated above, a crucial aspect of human action is that it is knowledgeable and reflexive. Agency refers to capability, not intentionality, although action taken by humans may have intended and unintended consequences. For example, a company's adoption of electronic mail may have the 
intended consequence of increasing communication and information sharing, and the unintended consequence of reducing status barriers and social context cues [Sproull and Kiesler 1986]. Further, while personal action of human agents using technology has a direct effect (intended and unintended) on local conditions, it also has an indirect effect (often unintended) on the institutional environment in which the agents are situated. For example, a person may use a spreadsheet program to compute an organization's annual revenues, or to create the impression of a legitimate business, but the effect of that action is to reaffirm the relevance and primacy of the "rules of accountability" established by the accounting profession. Even where actions are directly intended to preserve or change some aspect of the institutional environment, the result is not guaranteed. For example, managers may implement automated production procedures to reposition their organization competitively. The result may be that since the organization's operations are now much more dependent on the technology, they are also more vulnerable to technological breakdowns which disrupt workflow, increase costs and delays, and adversely affect customers.

\section{(ii) The Interpretive Flexibility of Technology}

As we saw above, the duality of technology has tended to be suppressed in organizational discourse in favor of a dualism which emphasizes only one view of technology. To some extent this myopia is fostered by the fact that one aspect of the duality is often invisible in organizations. With many types of technology the processes of development and use are often accomplished in different organizations. That is, many of the actions that constitute the technology are often separated in time and space from the actions that are constituted by the technology, with the former typically occurring in vendor organizations, and the latter occurring in customer sites. In these circumstances, it is not surprising that users of a technology often treat it as a closed system or "black box," while designers tend to adopt an open systems perspective on technology.

This time-space discontinuity is related to the notions of temporal scope that were examined above. The dualistic view of technology as fixed object or as product of human action is influenced by the different temporal stages of technology that investigators have chosen to focus on. Recognizing the time-space discontinuity between the design and use of technology gives us insight into how it has promoted the conceptual dualism dominating the literature (see Figure 4). Researchers examining the design and development of a technology (the left hand side of Figure 4) are confronted with the essentially constructed nature of the technology. They examine how technology designers, influenced by the institutional properties of their organization (arrow 1), fashion and construct a technology to meet managerial goals (arrow 2). Such studies are less likely to treat technology as fixed or objective, recognizing its dynamic and contingent features (as in the strategic choice studies). Researchers examining the utilization of a technology in an office or factory, on the other hand (the right hand side of Figure 4), focus on how users of technology are influenced by the 
given technology (arrow 3), and how the technology affects institutional properties of the organization (arrow 4): Such researchers are less inclined to focus on the human agency that initially produced the technology, and tend not to recognize the ongoing social and physical construction of technology that occurs during its use.

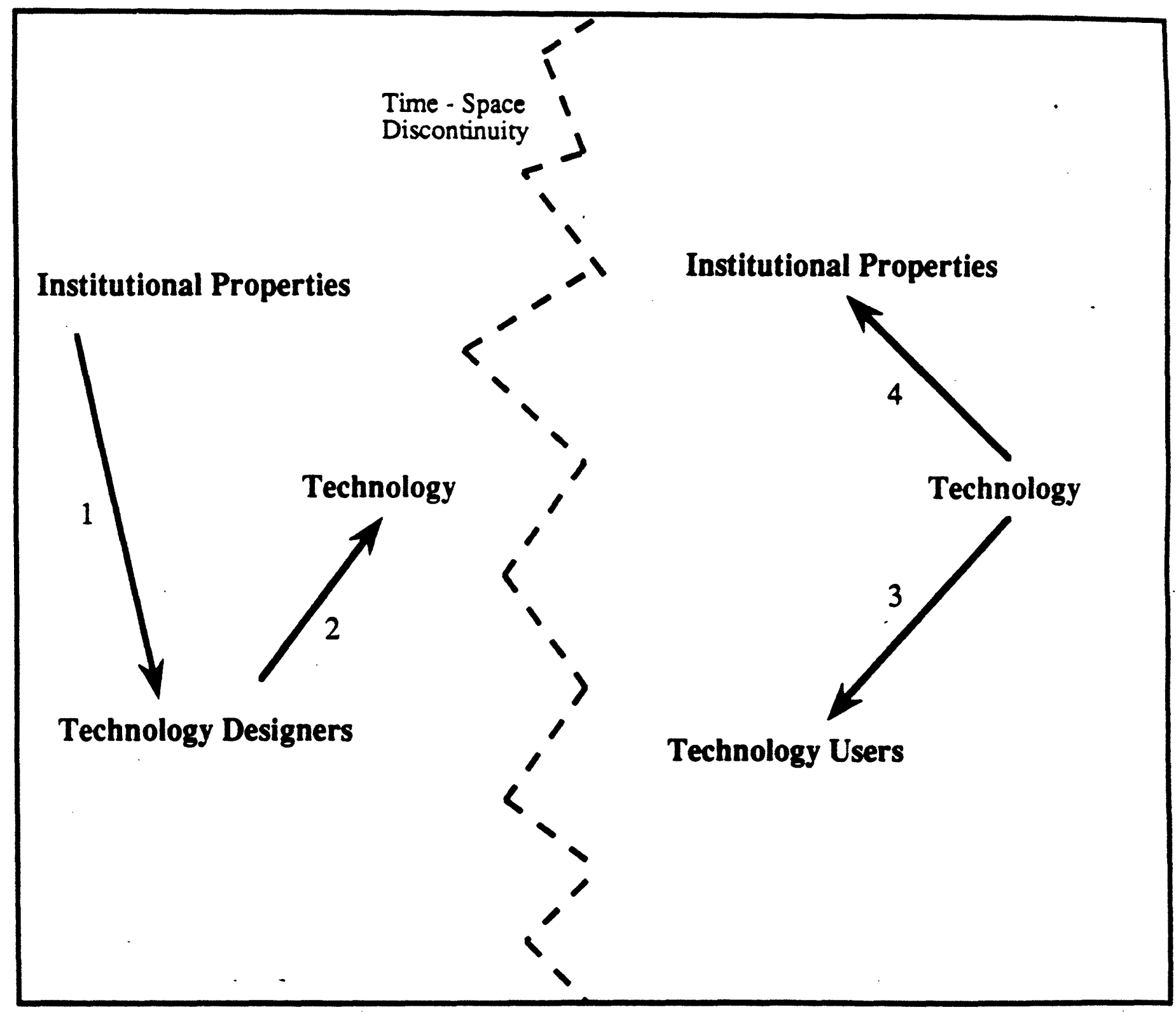

Figure 4: Traditional Models of Technology Design and Technology Use (discontinuous in Time-Space) 
Rather than positing design and use as disconnected moments or stages in a technology's lifecycle, the structurational model of technology posits artifacts as potentially modifiable throughout their existence. In attempting to understand technology as continually socially and physically constructed, it is useful to discriminate analytically between human action which affects technology and that which is affected by technology. I suggest that we recognize human interaction with technology as having two iterative modes: the design mode and the use mode. I emphasize that this distinction is an analytical convenience only, and that in reality these modes of interaction are tightly coupled.

Even as we recognize that technologies are designed and used recursively, we also need to acknowledge the differences among technologies in the degree to which users can effect redesign. While we can expect a greater engagement of human agents during the initial development of a technology, this does not discount the ongoing potential for users to change it (physically and socially) throughout their interaction with it. In using a technology, users interpret, appropriate, and manipulate it in various ways, being influenced by a number of individual and social factors. Despite these opportunities for engagement with technology, however, rigid and routinized views of and interactions with technology do develop. Such developments are a function of the interaction betweeen technology and organizations and are not inherent in the nature of technology.

For example, many technologies such as manufacturing and medical technologies, have assumed such a rigidity at their point of deployment--the factory floor or the hospital--that they appear to be fixed means of production. But even the most "black box" technology has to be apprehended and activated by human agency to be effectual, and in such interaction users shape technology and its effects. For example, Jönsson and Grönlund [1988] describe how machine operators participate in its testing and adaptation, while Wynne [1988] cites instances where operators of a range of technological systems--from airplanes to chemical plants--routinely deviate from formal, rulebound operating practices to deal with complex interdependencies, unanticipated events, and the contingencies of local conditions. The Challenger shuttle disaster is a case in point. The inquiry revealed that the space shuttle had often been operated with various malfunctioning components, and because 0 -ring damage and leakage had been experienced frequently during the shuttle flight history, "... the experts had come to accept it as a new normality" [Wynne 1988:151]. Wynne notes about this and the other technological cases: "The whole system can be seen to have been evolving uncertainly according to innumerable ad hoc judgements and assumptions. These created a new set of more private informal 'rules' beneath the discourse of formal rules and check procedures" [ibid.]. 
Examples of sabotage and avoidance of use in more rigid technologies such as assembly lines, chemical plants, anid power stations further illustrate the role of users shaping technology and its effects [Perrow 1983; Shaiken 1985; Wynne 1988], while studies of offices reveal similar pattems of users influencing technology through informal practices, avoidance behavior, or "working to rule" [Garson 1988; Howard 1988; Markus 1983; Zuboff 1988]. MacKay [1989] for example, describes how users of an electronic mail system employed different strategies for using it based on their different task contingencies and individual preferences. As a result, the technology was appropriated in diverse ways and came to have different meanings and effects for different users.

What is critical in discriminating between more or less rigid technologies is the capacity of users to control their interaction with the technology and its characteristics. Because users can potentially exercise such control at any time during a technology's existence, the apparent disjuncture between the design and use stages is artificial and misleading. I will use the term interpretive flexibility, following Pinch and Bijker [1984, 1987], to refer to the degree to which users of a technology are engaged in its constitution (physically and/or socially) during development or use. Interpretive flexibility is an attribute of the relationship between humans and technology and hence it is influenced by characteristics of the material artifact (e.g., the specific hardware and software comprising the technology), characteristics of the human agents (e.g., experience, motivation), and characteristics of the context (e.g., social relations, task assignment, resource allocations).

While the notion of interpretive flexibility recognizes that there is flexibility in the design, use, and interpretation of technology, the factors influencing it allow us to acknowledge that the interpretive flexibility of any given technology is not infinite. One the one hand, it is constrained by the material characteristics of that technology. Technology is at some level physical in nature and hence bounded by the state of the art in materials, energy, and so on. On the other hand, it is constrained by the institutional contexts (structures of signification, legitimation and domination) and different levels of knowledge and power affecting actors during the technology's design and use. For example, the initial designers of a technology have tended to align with managerial objectives [Markus and Bjøm-Andersen 1987; Noble 1984; Sterling 1982], with the result that many technologies reinforce the institutional status quo, emphasizing standardization, control, and efficiency. However, there is nothing inevitable about this alliance, and it may shift as the traditional division of labor between designers and users blurs with the increased deployment of computer-based artifacts [Hirschhom 1984; Shaiken 1985], and as users of technology grow in number, influence, and knowledge. It may also be influenced by changing economic conditions which may pressure managers to alter strategies, organizational forms, and operating norms. 


\section{Components of the Structurational Model of Technology}

The structurational model of technology comprises the following components: (i) human agents-technology designers, users, and decision-makers; (ii) technology--material artifacts mediating task execution in the workplace; and (iii) institutional properties of organizations, including organizational dimensions such as structural arrangements, business strategies, ideology, culture, control mechanisms, standard operating procedures, division of labor, expertise, communication patterns, as well as environmental pressures such as government regulation, competitive forces, vendor strategies, professional norms, state of knowledge about technology, and socio-economic conditions. The following discussion of the structurational model of technology makes reference to the relationships depicted in Figure 5.

I. Technology is the product of human action (arrow a). As a human artifact, technology only comes into existence through creative human action, and is sustained by human action through the ongoing maintenance and adaptation of technology (automobiles need servicing, typewriters require new ribbons, and even pencils need sharpening). Further, human action constitutes technology through using it. That is, once created, technology is deployed in organizations but remains inanimate and hence ineffectual unless it is given meaning and is manipulated--directly or indirectly--by humans. On its own, technology is of no import; it plays no meaningful role in human affairs. It is only through the appropriation of technology by humans (whether for productive or symbolic ends), that it plays a significant role and hence exerts influence. It is only through human action that technology qua technology can be understood.

The interpretive flexibility of technology operates in two modes of interaction. In the design mode, human agents build into technology certain interpretive schemes (rules reflecting knowledge of the work being automated), certain facilities (resources to accomplish that work), and certain norms (rules that define the organizationally sanctioned way of executing that work). In the use mode, human agents appropriate technology by assigning shared meanings to it, which influence their appropriation of the interpretive schemes, facilities, and norms designed into the technology, thus allowing those elements to influence their task execution. In many organizations, individuals may have little control over when or how to use technology, and hence little discretion over which meanings and elements influence their interaction with it. But, these constraints are institutional, and are not inherent in the technological artifact itself. Users can always choose (at the risk of censure) not to utilize a technology, or choose to modify their engagement with it. The notion that technology needs to be appropriated by humans retains the element of control that users always have (however slight) in interacting with technology. 
Figure 5: Structurational Model of Technology

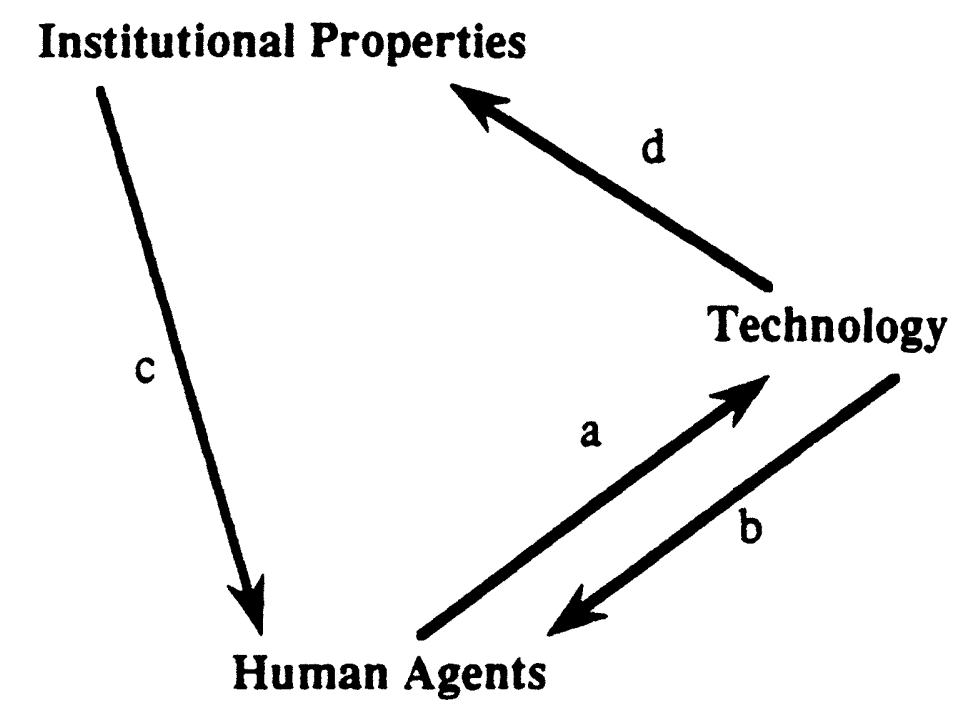

\begin{tabular}{|c|c|l|}
\hline Arrow & Type of Influence & \multicolumn{1}{|c|}{ Nature of Influence } \\
\hline a & $\begin{array}{c}\text { Technology as a Product of } \\
\text { Human Action }\end{array}$ & $\begin{array}{l}\text { Technology is an outcome of such human action as } \\
\text { design \& development, appropriation, and modification }\end{array}$ \\
\hline b & $\begin{array}{c}\text { Technology as a Medium of } \\
\text { Human Action }\end{array}$ & $\begin{array}{l}\text { Technology facilitates and constrains human action } \\
\text { through provision of interpretive schemes, facilities, } \\
\text { and noms }\end{array}$ \\
\hline c & $\begin{array}{c}\text { Institutional Conditions of } \\
\text { Interaction with Technology }\end{array}$ & $\begin{array}{l}\text { Institutional Properties influence humans in their } \\
\text { interaction with technology, e.g. intentions, design } \\
\text { standards, professional norms, state of the art in } \\
\text { materials and knowledge, and available resources (time, } \\
\text { money, skills) }\end{array}$ \\
\hline d & $\begin{array}{c}\text { Institutional Consequences of } \\
\text { Interaction with Technology }\end{array}$ & $\begin{array}{l}\text { Interaction with technology influences institutional } \\
\text { properties of an organization, through reinforcing or } \\
\text { transforming the structures of signification, domination, } \\
\text { and legitimation }\end{array}$ \\
\hline
\end{tabular}


II. Technology is the medium of human action (arrow b), because technology, when used by workers, mediates their activities. Anyone who has used a typewriter, telephone, computer, hammer, or pencil can attest that technology facilitates the performance of certain kinds of work. That the technology also constrains the performance by facilitating it in a particular manner is an important corollary of this. This influence resembles that posited by earlier examinations of the "impacts of technology" on the use of technology. However, there are two significant differences in the structurational model. One is the recognition that technology cannot determine social practices. Human agency is always needed to use technology and this implies the possibility of "choosing to act otherwise." Thus, technology can only condition social practices. The other difference is the acknowledgement that technology, in conditioning social practices, is both facilitating and constraining. Technology does not only constrain or only enable, but rather does both. This dual influence has typically not been recognized in studies that attempt to determine definitively whether technology has "positive" or "negative" effects [Attewell and Rule 1984; Hartmann et al. 1988]. Giddens' [1984] framework allows us to recognize that technology--as a medium of social practices--necessarily has both restricting and enabling implications. Which implication dominates depends on multiple factors including the actions and motives of designers and implementors; the institutional context in which technology is embedded; and the autonomy and capability of particular users.

Other influences that reflect the interaction between human agents and structural properties are also relevant to a study of technology use in organizations. However, to punctuate the key aspects of technology, only those influences directly involving technology are discussed here. Two such influences are particularly important in the structurational model of technology.

III. One influence concerns the nature of human action in organizations, which is situated action, and hence shaped by organizational contexts (arrow $c$ ). When acting on technology (whether designing, appropriating, modifying, or even resisting it), human agents are influenced by the institutional properties of their setting. They draw on existing stocks of knowledge, resources, and norms to perform their work. Often these influences are unarticulated, or reflected on only fleetingly by human agents [Giddens 1984], and are here referred to as the institutional conditions of interaction with technology. Anderson [1988] compared the development of numerically controlled (NC) equipment in two different contexts, the U.S. and Norway, and found that different institutional settings, funding, labor relations, socio-economic conditions, and cultural traditions shaped very different kinds of NC technologies. The case of the British watertransfer tunnel [Wynne 1988] described above, tragically reveals how particular institutional conditions influenced the design and development of a specific technology, while Barley's [1986, 1990] examination of how two different hospitals used similar medical scanning technology, 
shows how different institutional conditions influenced the way people interacted with technology. Technology is built and used within certain social and historical circumstances and its form and functioning will bear the imprint of those conditions.

IV. The final influence involves the manner in which human action when it uses technology acts upon the institutional properties of an organization (arrow d), either by reinforcing them (more typically) or by transforming them (less frequently). Technology is an "enacted environment" [Weick 1979:260] whose construction and use is conditioned by an organization's structures of signification, domination, and legitimation. The appropriation and use of technology implies the change or reinforcement of these three institutional structures. These effects--comprising the institutional consequences of interaction with technology--are often not reflected on by users, who are generally unaware of their role in either reaffirming or distupting an institutional status quo. When users conform to the technology's embedded rules and resources, they unwittingly sustain the institutional structures in which the technology is deployed.

When users do not use the technology as it was intended, they may undermine and sometimes transform the embedded rules and resources, and hence the institutional context and strategic objectives of the technology's creators, sponsors, and implementors. This may happen more frr juently than one would imagine. Perrow [1983] and Wynne [1988] show how users operating complex technologies often have to deal with high levels of stress, ambiguity, and unstructured local situations that deviate from "normal" operating conditions. In these situations, the negotiated or enacted use of technology is often very different to the prescribed, mechanical operation of the technology. Wynne notes [1988:152]: "Thus implementing design commitments and operating technological systems involves the continual invention and negotiation of new rules and relationships, not merely the enactment of designed ones. This develops the technology in unanticipated ways, as it is 'normalized'." Tyre's [1988] study of process technology includes the case of a new grinding machine being introduced into an automated manufacturing plant. Intital integration problems forced project engineers to install a temporary manual "workaround." Although the manual workaround was inefficient, operators quickly learned to depend on it to accomplish their work. Later, when the grinder was fully functional, operators prevented the engineers from dismantling the "temporary" workaround. The new technology with its workaround had become so integrated into operators' routines, that it become the "normal" or institutionalized mode of operating the grinding machine.

In the model of technology proposed here, structuration is understood as a dynamic process which is embedded historically and contextually. While the main components and nature of relationships underlying this model are considered relatively stable, their range, content, and relative power will 
vary over time. In addition to being dynamic, structuration is understood to be a dialectical process, hence inherently contradictory. In contrast to models that relate elements linearly, the structurational model assumes that elements interact recursively, may be in opposition, and that they may undermine each other's effects. An example is the tendency of technology to become reified in organizations, thus becoming detached from the human action that constructed it. The typical apprehension of technologies as given and objective directly contradicts their inherently constructed nature. Recognizing potential contradictions helps us to understand points of tension and instability in organizations, and how these may interact to change and transform organizations.

\section{USING THE STRUCTURATIONAL MODEL OF TECHNOLOGY}

This section illustrates the structurational model of technology by interpreting the findings of a field research study [Orlikowski 1988], which investigated the use of information technology in a large, multi-national software consulting firm, Beta Corporation.

\section{Research Site}

In 1987, Beta earned $\$ 600$ million dollars in worldwide consulting fees and employed over 13,000 consultants in some 200 offices in over 50 countries. Most of Beta's employees are "functional consultants" who engage in the building of customized application systems for clients. A small proportion (three percent in 1987) are "technical consultants" who provide technical support (expertise in hardware and systems software) to the functional consultants, and engage in research and development. Beta consultants operate in temporary project teams and occupy various levels in the firm hierarchy (consultant, senior consultant, manager, and senior manager). ${ }^{1}$ Over the last few years Beta has invested extensive amounts of information technology in the production work of its consultants. This investment has transformed application systems development--traditionally a labor-intensive, paper-based set of activities--into a rationalized, capital-intensive production process. The specific kind of information technology developed to automate systems development is known in the data processing industry as "Computer-Aided Software Engineering" (CASE) technology, and in Beta as "productivity tools."

\section{Research Methodology}

The study employed ethnographic techniques [Agar 1980; Van Maanen 1979, 1988] such as observation of participants, interaction with CASE tools, documentation review, social contact, unstructured and semi-structured interviews. It was executed over eight months within Beta and in those client sites where Beta developers were building application systems. In the first phase of the research, historical data on the Beta corporation and its systems development practices was

\footnotetext{
${ }^{1}$ In the following, a reference to ' :onsultants" refers to functional consultants, unless otherwise indicated.
} 
gathered from published material (inhouse and trade press), and from interviews with senior managers who had been involved in Beta's traditional systems development, as well as its adoption of a capital-intensive systems development process. With some background information on Beta and its practices, five different application projects (four large and one small) were selected for indepth analyses. Projects were not selected at random but were strategically identified to guarantee exposure to the use of CASE tools in all major phases of the systems development life cycle (requirements analysis, conceptual design, detailed design, implementation, and testing).

An average of four weeks was spent on each project, observing and interviewing team members in their daily systems development work, and in their interaction with each other and the CASE tools. One hundred and twenty formal interviews were conducted, each lasting an average of one and a half hours, and many more informal meetings and exchanges took place. Participation in the research was voluntary and while the particular projects studied were approved by Beta's senior management, individuals spanning all Beta's hierarchic levels were invited to participate in the study by the researcher alone. Other key informants were identified and sought out both within and outside Beta, such as the senior recruiting officer, the director of research and development, sales directors, major client managers, and former Beta employees. Data was also collected throughout the study at monthly (all day) division meetings, and in project training sessions on CASE tools.

We can examine Beta's development and use of productivity tools in terms of the processes through which the technology was integrated into Beta's operations over time. These processes will then be interpreted through a series of structurational models, depicted in Figures 6 through 8 .

\section{Stage I: Initial Development of Technology}

About a decade ago, Beta's senior managers decided that to maintain their profitability ratio and beat the competition they needed to increase productivity, hence decreasing the length of systems development, and reducing the number of consultants required on each project. They also wanted to improve management leverage by increasing the number of consultants per senior manager (expanding span of control). They also wanted to diminish their dependence on the technical knowledge required for the multiple different computer configurations operated by their clients. In the past, Beta had to ensure that consultants knew a range of programming languages, database management, teleprocessing, and operating systems to be sufficiently versatile to operate in many technological environments. Such knowledge is highly technical, idiosyncratic, and quickly becomes obsolete as new computer products continually appear on the market.

The task of constructing productivity tools was delegated to Beta's technical consultants, who constructed computer routines that encoded knowledge of systems development. In order to 
automate Beta's systems development practices the technical consultants had to articulate and rationalize the existing manual procedures that functional consultants utilized daily in their work. In this they were helped by the existence within Beta of a systems development methodology, which specified in great detail the rules and routines for executing each systems development task.

When Beta first began consulting in the early sixties there were no formal standards or guidelines by which software consultants conducted their practice. Application systems were built by trial and error. Over time, a body of inhouse systems development knowledge accumulated through the sharing of experiences, and some informal checklists were compiled and circulated. But the software consulting practice kept growing (about 150 percent annually) and Beta acquired more personnel and clients. The informal tradition with which Beta's practice guidelines were learnt and communicated was no longer adequate. The guidelines were too open-ended, assumed too much competence, and could not deal with exceptional conditions. Projects had become bigger and more complex, the stakes higher, and losses more severe and visible. In response, Beta managers set up a firm-wide task force to codify the informal systems development heuristics, expanding them where appropriate, and formally instituting practice guidelines. Thus, Beta's official and comprehensive systems development methodology was created. It prescribed a sequence of systems development stages, articulated the tasks and deliverables of each stage, defined the skills needed to perform the tasks, established guidelines for estimating time and budgt ' requirements, and specified quality controls and process milestones. While prescriptive in documentation, the tenets of the methodology were often overridden in practice, with consultants relying on their initiative to perform work, using the methodology primarily as an orienting device.

An important condition for the rationalization of systems development work and hence the development of the technology was the prior institutionalization of Beta's systems development methodology. Despite the lack of congruence between the prescriptions of the methodology and systems development practice, the technical consultants turned to Beta's systems development methodology for a rational, structured, and thorough account of systems development work. While the tools were intended to standardize consulting work, in fact, the standardization had f receded the development of the tools. The tools gave management an opportunity to push standardization further, and more importantly, to enforce it in practice, which had not been feasible before.

The development of productivity tools within Beta can be described in terms of the structurational model (see Figure 6). Commissioned by senior management, technical consultants were influenced in their development work by their managers' strategy. This management strategy authorized the allocation of resources to technical consultants facilitating their construction of tools. This construction was also influenced by Beta's extant systems development methodology which 
provided the interpretive schemes and norms that technical consultants drew on to develop the productivity tools. The productivity tools were thus produced through the human agency of Beta's technical consultants (arrow 1). In order to achieve this construction, the technical consultants' actions were influenced by Beta's institutional properties (arrow 2), most notably the existing institutionalized knowledge and norms of Beta' systems development methodology (structures of signification and legitimation), and the resources (time, money and authority) distributed to the technical consultants by senior managers (structure of domination).

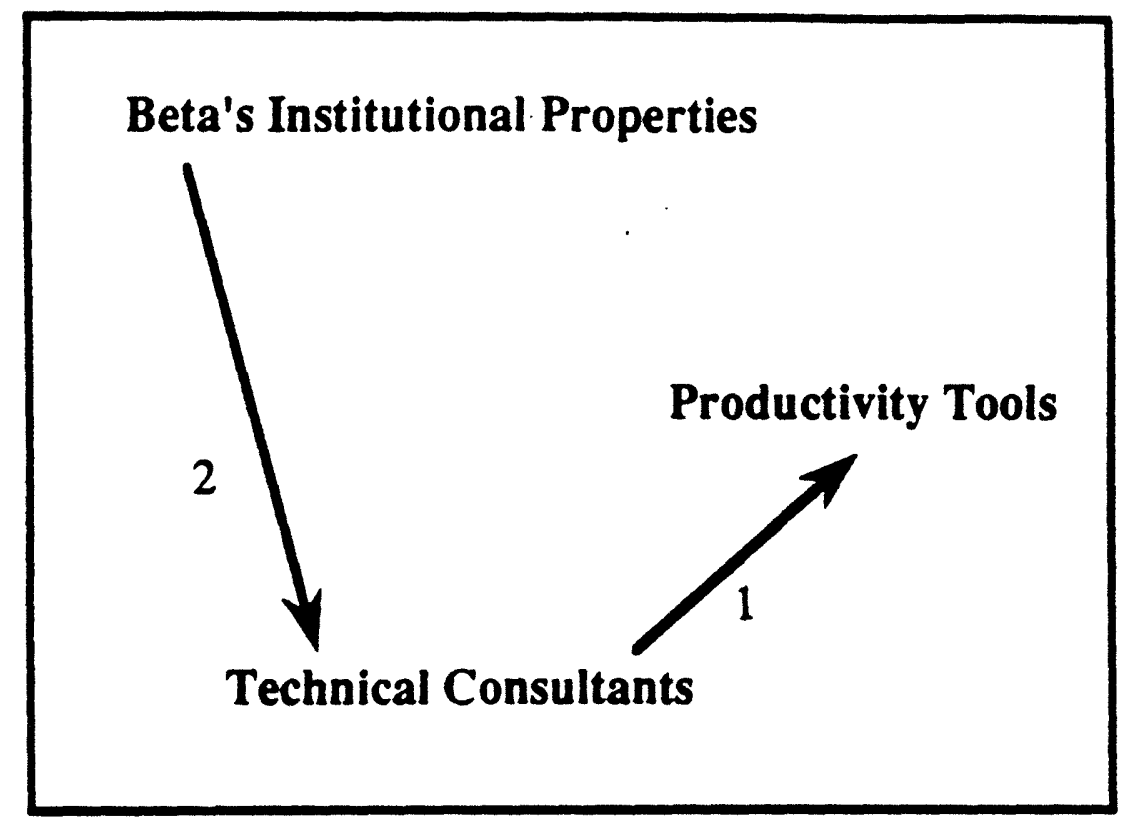

Figure 6: Structurational Model of Beta's Initial

Development of Productivity Tools

\section{Stage II: Institutionalized Use of Technology}

Once developed, the productivity tools were deployed on project teams. The diffusion of these tools was incremental at first, until the technology proved sufficiently robust to become mandatory on all large projects. When consultants use tools, their systems development work is mediated by the assumptions and rules built into the tools. As a medium of human action, the tools can be seen to both constrain as well as facilitate the activities of consultants. The technical consultants designed and built the tools so that work is executed in a standardized, structured, and predictable manner, which leaves little discretion in the hands of individual consultants. The tools also reflect the assumptions of management and technical consultants that the process of systems development is rational, sequential, and unambiguous, that consultants should interact passively with tools, and that they have little technical understanding of computer systems. The effect of such design decisions is that the technology disciplines the consultants' execution of their systems development tasks (arrow 3 in Figure 7). 


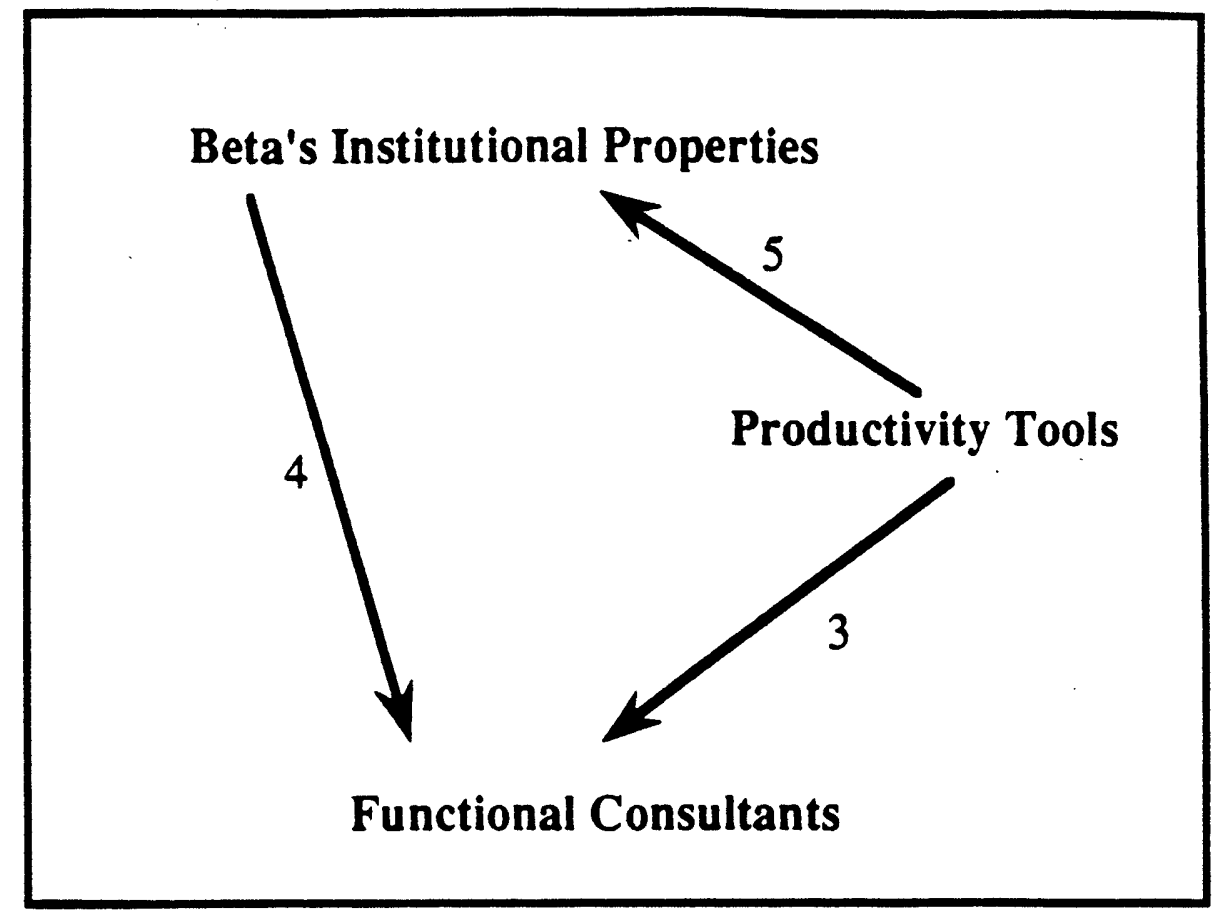

Figure 7: Structurational Model of Beta's Initial Use of Productivity Tools

For example, consider the task of interface design. Prior to Beta's deployment of tools, screens were designed manually, either on paper or via laborious manual manipulation on video display units. Consultants would design screens by positioning data fields in appropriate areas of the display, styling each field to the requisite format, and personally ensuring that appropriate standards and conventions were adhered to. Screen design was a time-consuming and individualized task. As one senior manager explained, tools rationalized this process in order to:

... enforce ergonomic designs of screens. We want to get consistently good designs, and if we leave it up to the consultants, we wouldn't get any consistency. Well, some of them may be Michelangelos, but then they could also be Jackson Pollacks!

With tools, consultants merely invoke the screen design tools on their workstations and in response to the tools' prompts, enter the data fields to be used in each screen. The screen design tools, programmed with a sophisticated algorithm, determine (via predefined "ergonomic heuristics") the most appropriate layout and formatting of fields on the screen. Screen designs are then automatically generated. Significant time savings are achieved, as well some flexibility. For example, if a consultant subsequently realizes that a data field has been inadvertently omitted, it is a simple matter to invoke the tools, change that screen's input parameters, and have the tools generate a new design. Without tools, such changes had to be done manually, and were tedious and time-consuming. 
This example demonstrates the role of technology as both an enabler of, and a constraint on, human action. On the one hand, tools allow the consultants to design screens more quickly than before, relieving them of the monotonous task of formatting fields, and further assisting modifications as these are required. On the other hand, the tools constrain the consultants in that they are limited to the formatting options available in the tools' repertoire. Screens that do not match the predefined templates cannot be designed within the scope of the tools, and institutional pressures within Beta (arrow 4 in Figure 7) operate to discourage consultants to bypass the tools and manually create unique screen designs. Consultants are expected to use the tools in their work, and deviating from this organizational norm typically results in a reprimand. Further, Beta's projects operate under extremely tight schedules, which compel consultants to perform work in the standard way because this is easier and quicker. Executing work differently is inconvenient, disruptive of schedules, hence to be avoided. A consultant reported:

In the front-end when we were designing with the screen and report design editors, we found we were leading clients on to accept the screens and reports in certain formats, because that's the way the design tool wants it done. So sometimes the client was forced to accept designs because of our technical environment.

This constraint encouraged consultants to try to persuade clients to accept the screen formats that had been generated by the tools. A typical tactic was to invoke the "technological imperative": It has to be that way; that's ti.z only way the tools will work. That screens could be manually custom-designed was not mentioned, and computer-naïve clients were mistakenly led to believe that the technology is deterministic. It was not only much easier for consultants to accept the tools' prescriptions than having to custom-produce the screen designs preferred by clients, but this also meant that their individual schedules were not disrupted. So consultants, pressured as they are by their project managers' work plans, put pressure on clients to accept those designs that are automatically generated by the tools. It seems that the "technological imperative"--rather than being an inherent aspect of technology--can be socially constructed, a product of the social practices that evolve around the use of a technology.

From the perspective of the individual consultants, the tools constrain their work because executing the various tasks of systems development requires conforming to the dictates of the tools. Systems development work which is mediated by a technology that emphasizes standardization, is no longer performed under the discretion of individual consultants. In the manner in which Beta has implemented productivity tools to mediate systems development, not only is task execution influenced, but also cognition about the task. Most consultants, particularly recruits, do not recognize the way in which tools generate processes of reality construction both for themselves and the clients whose jobs are being automated. Since the deployment of tools in Beta, systems 
development has come to be understood as an activity essentially performed by means of productivity tools. Tools have become a mechanism for technical control, delimiting the ways consultants perceive and interact with their work.

Once use of the productivity tools is taken for granted, they have become institutionalized, and their use by consultants in project work influences Beta's institutional structure (arrow 5 in Figure 7). In terms of the structurational model, the tools represent a set of rules and resources drawn on by organizational members in their everyday action, hence comprising part of Beta's structures of signification, domination, and legitimation. Tools contribute to Beta's structure of signification because the knowledge embedded in them (in the form of concepts and procedures) directs the manner in which problems are interpreted and work is conducted. Thus, when consultants use the tools they are subscribing to the interpretive schemes that constitute Beta's systems development knowledge. This was intentional, as a senior manager noted:

By building standards into tools we can control what people do and how they do it. We are no longer dependent on the knowledge in people's heads. So if people leave, we aren't sunk. Tools allow us to put knowledge into a structure and embed it in technology.

The tools' influence on action is not unnoticed by the consultants. A senior consultant observed:

Tools force people to think in a certain way. We all think screens and reports. So we don't have a chance to think if things could be done a better way. ... Tools have definitely stopped me thinking about other ways of doing things. We bring the same tindset to the different projects, so we already know what to do.

while a consultant remarked similarly:

When you rely on tools you inherently assume certain things, and hence this hinders your ability to see other things. To make an analogy, it's like playing with a pack of cards: you have to pick a card out of the 52 available; you can't pick the 53rd. So tools create a structure to work with, but we fall into the trap of not seeing beyond it.

Tools contribute to Beta's structure of domination because they constitute resources which are deployed in order to control the work of consultants. While implemented locally in each project, the productivity tools were designed and built centrally by the technical consultants. Through the tools' inbuilt assumptions, features, and standardized procedures they exert unobtrusive control over the nature of work, and the coordination of consultants on projects. As far as Beta is concerned, the primary production process has become too critical to risk autonomous action at project level. The technological infrastructure provided by the tools at each project, serves to institutionalize a mechanism of centralized control within Beta. Without human agents actively utilizing the technology, however, the centralized control invested in it is ineffectual. Consultants have to appropriate the tools in order to activate the centralized control, and in so doing they unintentionally reinforce the institutionalized control imposed on them through the technology. Thus, an unintended consequence of each use of the tools is the reaffirmation of Beta's system of 
domination. Of course, where consultants choose not to use the tools in the authorized manner, or choose to bypass the tools altogether (see below), they undermine this system of domination.

Tools contribute to Beta's structure of legitimation because they sanction a particular mode of developing systems, and propagate a set of norms about what is and what is not acceptable "professional" social practice. In mandating productivity tools on all large projects, Beta is sending a message that tools are the only legitimate way of developing large systems. Hence, the very deployment of technology within Beta is an application of a normative sanction. By implementing technology to support or automate work, management signals that the technology is an appropriate means for executing that work. Further, the rules embodied within the tools incorporate certain norms about the appropriate criteria and priorities to be applied to systems development work, and the manner in which the work is to be conducted. In applying productivity tools to systems development, the priorities, assumptions, and values embedded in the tools act as a moral imperative, comprising elements in Beta's system of legitimation.

In the case of Beta, unreflective use of the productivity tools is a very effective way of controlling the cognitions and actions of consultants. Beta's commitment to using a standardized development approach can be seen as an aspect of firm ideology as well as strategy. Tools are clearly not only instrumental (structuring the productio process) they are also normative, as they mediate a shared reality within Beta, producing uniformity and predictability in thought and behavior. And this is important for building solidarity and communal norms, and for rendering consultants interchangeable and dispensable. A senior manager suggested that tools:

... provide a basic language so we can all relate to the vocabulary and the norms of action. Our conceptual appreciation is the same, so we can substitute people on projects easily.

Because the norms of interaction are embedded in the tools, each interaction is highly efficient-minimizing the need for clarification or amplification--and effective--serving to reinforce Beta's shared reality, assumptions, and values. The result typically is a reaffirmation of the status quo, a reinforcement of Beta's system of legitimation.

\section{Stage III: Ongoing Interaction with the Technology}

The productivity tools were designed and implemented by Beta managers and technical consultants to increase efficiency of production work through rationalization and standardization. Today, productivity tools serve to constitute the development work of thousands of Beta's consultants, who were not involved in the development of the tools. This encourages a passivity and resultsorientation among the consultants (aided and abetted by Beta's competitive incentive system) that discourages reflectiveness. Notwithstanding such effects, however, knowledgeable and reflexive human agents are capable of altering the controlling influence of the technology. The extent to 
which individuals modify their use of technology, however, depends on whether they acknowledge its constructed nature. This is determined by the degree to which individuals can recognize the mediating role of technology, can conceive of an alternative beyond it, and are motivated to action.

At the current stage of tool use and development in Beta, the tools have not yet matured as fully standardized products (breakdowns still occur and local adjustments are often needed on projects). However, when tools become "seamless" as a manager described Beta's goal to fully integrate the tools into systems development work, their identification as means of production, distinct from the activities and outcomes they facilitate, will be far more difficult. As tools become more taken for granted than they are already, the ability for consultants to reflect on them and hence act without or beyond them, becomes more remote. Relevant here is Heidegger's [1962] notion of present-athand, which notes that objects typically form part of the background of an activity, without our explicit recognition of them as separate objects, and it is only when the objects break down that they confront us with their existence. The more tools "seamlessly" facilitate systems development, the more they will be taken for granted, and the more they are used unreflectively the more they will constrain human action [Berger and Luckmann 1967:62].

Human agency, however, through the dialectic of control an act against the apparent determinism of institutionalized artifacts. If users acknowledge that technology is interpretively flexible, they can modify their interpretation and use of it. Given most of the consultants relatively low levels of technical experience, Beta's institutional context with its centralized control mechanisms and standardized work procedures, and the relatively rigid design of the technology, use of Beta's productivity tools tends to be characterized, on the whole, by low interpretive flexibility. Some consultants however, are able to recognize the constructed nature of the tools they use--either because they are computer science graduates or had experienced systems development unmediated by tools--and on occasion they do attempt to modify their interactions with the tools.

Consultants reacted against the tools when they believed the tools imposed unreasonable constraints on their behavior. For example, consultants could not initiate certain tasks unless some other tasks in a certain sequence had been completed first and to a level of completeness specified by the tools. Perceiving this as unnecessarily time-consuming, consultants would often circumvent the tools in order to get on with the work they wanted to do. They occasionally even resorted to subterfuge. On one Beta project, the consultants perceived the tools to be particularly limiting, and manipulated their access to the underlying computer system in a way that allowed them to surreptitiously bypass the tools. After this covert action had gone on for a while (about a month) it was eventually detected and eradicated. A senior consultant remarked: 
... when all this came out, a big political stink blew up. We were told we weren't team players.

In this incident the consultants managed to convince their project managers that tools were unduly restrictive, and a few technical consultants were assigned to modify the functionality of the tools. A partial victory had been won for the consultants who, by not merely reinforcing Beta's institutional structure, had disrupted the taken-for-granted meaning system, power relations, and norms operating within the project. They had altered the functioning of the tools--typically perceived to be the purview of technical consultants--and assumed some control over their task execution. As a result they had forced a change in the technology which gave them a little more discretion in how and when they used the tools. This example indicates how technology cannot be conceived as a fixed object at any stage during its deployment; its features and implementation patterns can and do change over time through human intervention.

Whether disruption of Beta's institutionalized properties is short-term or long-lived depends on the extent to which the deviation from established structures is sustained, and the extent to which the deviant action diffuses throughout the firm. The likelihood of consultant noncompliance within Beta--while always present to some degree--may be diminishing in the future. More and more of the consultants, trained only to use tools, are not learning technical skills or getting systems development experience without tools, so it is unikely that many of them will realize that systems development could be done differently, and they will be less inclined to try to alter the technology as they utilize it in their daily work. The contradictory nature of technology is apparent here: tools were built to improve productivity on Beta projects, yet their use creates consultants who are only productive with tools, and who have a "trained incapacity" to do systems development work in any other way, or to recognize when the tools inhibit productive or effective work.

Figure 8 depicts Beta's ongoing interaction with its productivity tools. To conduct their systems development work, functional consultants appropriate tools to execute their development work (arrow 6). Their appropriation of the tools is influenced by Beta's institutional context and their socialization into it (arrow 7). In using the tools, the functional consultants' action and perceptions of reality (of their work, of the tools, of themselves and their clients) are mediated (facilitated and constrained) by the interpretive schemes, norms, and resources embedded in the productivity tools (arrow 8). Executing systems development work through the tools typically reaffirms Beta's institutional properties, as expressed in its structures of signification, domination, and legitimation (arrow 9). Occasionally however, the functional consultants may deviate in their appropriation of the tools (arrow 6), by choosing to disregard or modify their interaction with the tools. This action undermines the interpretive schemes, norms, and resources embedded in the tools, and, if sufficiently vigorous and sustained, may transform Beta's institutional properties by altering 
aspects of the structures of domination, signification, or legitimation (arrow 9). This may trigger a change in management strategy, so that managers may authorize technical consultants to modify the tools (arrow 7). This would change the form or functioning of the tools (arrow 6), but once deployed, tools would again become institutionalized and serve to condition the work of the functional consultants (arrow 8), while also reproducing Beta's institutional systems (arrow 9). This dialectical cycle of relations and interactions between consultants, Beta's institutional properties, and the technology will continue over time, for as long as the productivity tools remain a component in Beta's operating strategy.

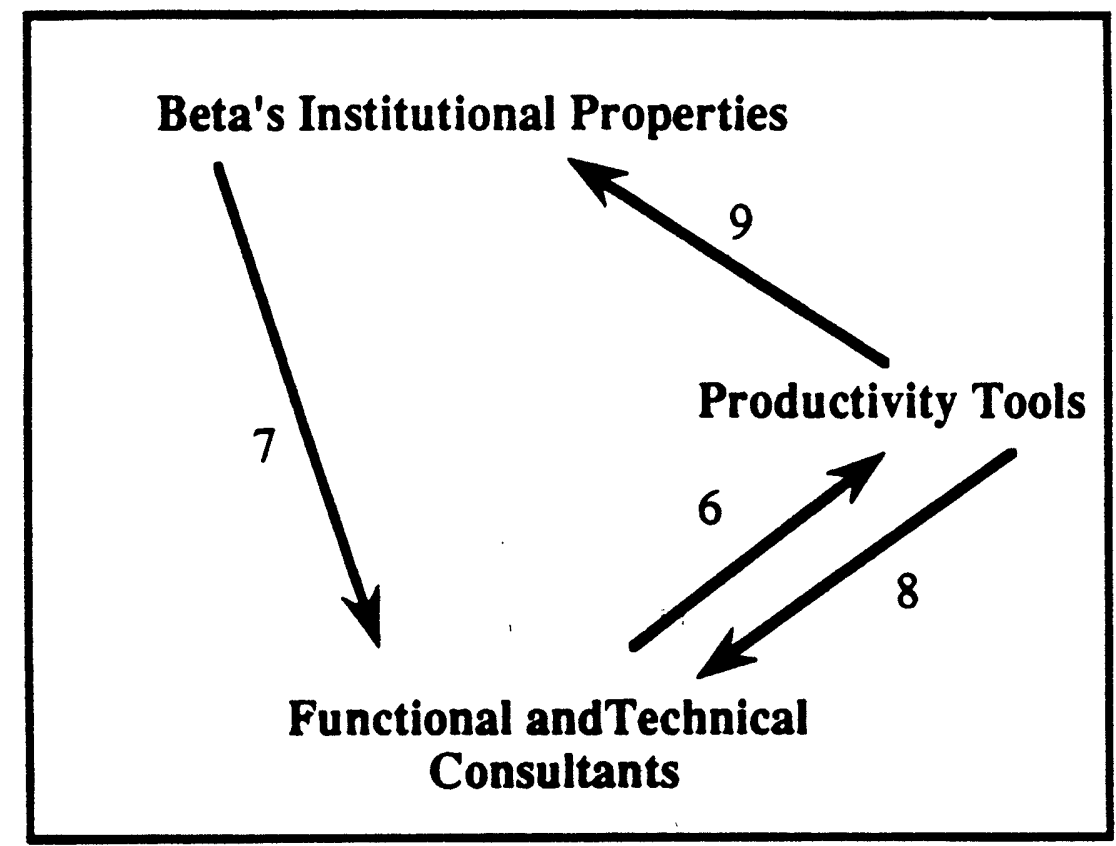

Figure 8: Structurational Model of Beta's Ongoing Interaction with Productivity Tools

\section{DISCUSSION}

This paper has explored a number of issues that change the way we think about and study the interaction of technology and organizations. In particul ir, two key aspects of technology have been highlighted, the duality of technology and its interpretive flexibility, both of which have typically been masked by the time-space disjuncture implicated in different stages of a technology's interaction with organizations. The duality of technology allows us to see technology as enacted by human agency and as institutionalized in structure. It further focuses attention on the physical and historical boundedness of any technological innovation. Technologies are products of their time and organizational context, and will reflect the knowledge, materials, interests, and conditions at a given locus in history. There is nothing inevitable or inviolable about them [Noble 1984; Perrow 1983; Zuboff 1988]. 
The time-space disjuncture prevalent in prior conceptualizations of technology is collapsed here by understanding that technologies have different degrees of interpretive flexibility. This emphasizes that there is flexibility in how people design, interpret, and use technology, but that this flexibility is a function of the material components comprising the artifact, the institutional context in which a technology is developed and used, and the power, knowledge, and interests of human actors (developers, users, and managers). Time too, influences the interpretive flexibility of technology, as the interpretation and use of technologies in organizations tend to be habitualized and routinized over time, beconing less open to conceptual and operational modification. Such closure typically becomes sanctioned and institutionalized, in which case the technology assumes a solidity and stability that belies its potential interpretive flexibility.

The conceptual closure and reification of technology in organizations is exacerbated by the tendency in industrialized economies to separate technological development from use, so that many of the technologies that mediate work in organizations arrive fully formed on the factory or office floor. The greater the temporal and spatial distance between the construction of a technology and its application, the greater the likelihood that the technology will be interpreted and used with little flexibility. Where technology developers consult with or involve future users in the construction and trial stages of a technology, there is an increased liki ihood that it will be interpreted and used more flexibly. This should be even more the case where developers of a technology are also users of that technology, for example where craftsmen make their own tools or where users of software design and construct their own computer applications.

The concept of interpretive flexibility with respect to technology is particularly pertinent in the light of increased deployment of computer-based technologies in organizations. Such technologies operate by manipulating symbols, and as a consequence, vendors and designers have found it costeffective to construct more "open-ended" technologies, than has been the case with industrial ones. For example, information technology is typically constructed and sold by vendors as a generalpurpose computing capability on which different applications are constructed and modified by customers over time. Industrial technologies, on the other hand, have tended to be cheaper and more efficient to produce and use with fixed and standardized components. However, there is nothing inherent about industrial technologies that requires greater closure and rigidity. If a sufficient amount of resources would be invested in them, they too could support a greater range of interpretations and uses. To date, management has not found it feasible to do so. But information technologies are changing the economies of production and use [Child 1985; Jonscher 1988], and the cost constraints that prohibited more flexible industrial technologies are diminishing with the general shift in many industries towards computer-based technologies. 
While economic and technological factors are encouraging a movement away from constructing and deploying relatively rigid artifacts, it is not clear that social and cultural factors are equally encouraging. The culture of the workplace, managerial ideology, and existing bases of expertise and power significantly influence what technologies are deployed, how they are understood, and in which ways they are used. Powell [1987:196], citing comparative research into U.S. and Japanese flexible manufacturing systems, notes: "The United States, it appears, is finding that the mass production ethos is very hard to escape. ... Japanese workers and managers have a much greater understanding of what modern technology can do and rely far more on the judgement of people on the shop floor." Similarly, many organizations do not exploit information technology's potential interpretive flexibility, tending often to construct inflexible software applications [Garson 1988; Zuboff 1988]. As the examination of Beta's productivity tools revealed, information technology can be designed, interpreted, and used with relatively low interpretive flexibility to meet the objectives of senior management.

While Giddens' [1984] theory of structuration is posed at the level of society, his structuration processes, describing the reciprocal interaction of social actors and institutional properties are relevant at multiple levels of analysis. The structurational model of technology allows us to conceive and examine the interacti 1 of technology and organizations at interorganizational, organizational, group, and individual levels of analysis. This overcomes the problem of levels of analysis raised by a number of commentators [Kling 1987; Leifer 1988; Markus and Robey 1988; Rousseau 1985], and underscores the value of understanding the multiple levels across which technology interacts with organizations. Only examining selected relationships--e.g., how technology influences human agents without being mindful of how users appropriate that technology--leads to a partial understanding of technology's interaction with organizations.

By moving across levels of analysis and boundaries of time and space, the structurational model of technology affords an examination of technology transfer among organizations. Many of the technologies used by organizations today are not built internally. Rather they are acquired from other organizations--either custom-designed, off-the-shelf, or in some form that is part massproduced and part customized. Recognizing the disjuncture in time and space between the design and use mode, allows us to analyze the role of multiple organizations in developing and deploying a particular technology. A technology may be designed by one organization, built by a second, and then transferred into a third for use. In these cases, the institutional conditions and human agents involved in technology development are different to those involved in technology use. That is, external entities--the developing organizations--play an influential role in shaping the social practices of the organizations using the technology. Within Beta, for example, the tools were 
developed inhouse so there was no other organization influencing the development of the technology. However, Beta does sells its tools to clients, and in this transfer of technology the institutional properties embedded within Beta's tools, shape the cognitions and actions of tool users in client organizations, and potentially shape the institutional properties of those client organizations. The structurational framework affords a way of investigating not only the movement of technology through time-space, but also across organizational boundaries, potentially providing a basis for analyzing interorganizational relations of learning, influence, and dependence. ${ }^{2}$

The structurational model of technology does not directly deal with organizational form, which was considered an institutionalized property of organizations. Future analyses of the relationship between different organizational forms and the interaction of technology and human agency are clearly relevant. It would be useful to isolate this aspect of organizations analytically and examine how different organizational forms may engender certain kinds of technologies, and how these technologies in turn may reinforce or transform the structural configurations over time. For example, we could postulate that more or less interpretively flexible interactions with technology would be associated with the various organizational forms posited by Mintzberg [1979].

One might further speculate that if some of the underlying assumptions about the separation of technology development and use are discarded by organization because of changing economic conditions or new strategic initiatives, and as technologies become more amenable to design and development by users, some of the traditional forms of organizing may be modified. For example, the role and power of the technostructure in designing and deploying relatively stable technologies for use by workers may change, as workers are given the discretion, knowledge, and resources to manipulate their technologies. As organizations struggle and learn to be more flexible in turbulent times, different assumptions about and diverse interactions with technology may both shape and be shaped by new forms of organizing. Empirical research is needed to determine the forces motivating the conception, development, and use of technologies with different degrees of interpretive flexibility, and to assess their interaction with social practices and organizational forms.

\section{CONCLUSION}

This paper has proposed an alternative theoretical conceptualization of technology which underscores its socio-historical context, and its dual nature as objective reality and as socially constructed product. This paper details and illustrates a structurational model of technology that can inform our understanding and future investigations of how technology interacts with organizations.

2 I would like to thank one of the anonymous reviewers for this insight. 
The structurational view of technology provides insights into the limitations and contributions of prior conceptualizations of technology. In particular, we can see how each of the prior traditions were partially correct, but also one-sided. The technological imperative school, perceiving technology to be a given, objective reality, provides insight into how technology is used, and how, in this use mode, it plays a deterministic role. The strategic choice school, perceiving technology to be a dynamic, human construction, provides insight into how technology is developed and intepreted, and how through this construction it reflects social interests and motivations. The view of technology as an occasion for structural change provides insight into how the socio-historical context influences the interaction of humans around the use of a technology.

The structurational model of technology is intended to punctuate key aspects of the technology phenomenon, and suggest typical relationships and interactions surrounding its development and use. Even though causal associations may be postulated and investigated, the premises of the structurational model caution us against undue determinism. While expected relationships may hold empirically for certain organizations in certain historical and socio-economic conditions, the everpresent ability of actors to alter the cycle of development, appropriation, institutionalization, and reproduction of technology may undermine any causal expectations. The ongoing interaction of technology with organizations must be understood dialectically, as involving reciprocal causation, where the specific institutiol ' context and the actions of knowledgeable, reflexive humans always mediate the relationship.

This view of technology encourages investigations of the interaction between technology and organizations that seek patterns across certain contexts and certain types of technology, rather than abstract, deterministic relationships that transcend settings, technologies, and intentions. As the field study shows, there are strong tendencies within institutionalized practices that constrain and facilitate certain developments and deployments of technology. In particular, understanding how different conditions influence the development, maintenance, and use of more or less interpretively flexible technologies would give insight into the limits and opportunities of human choice and organizational design.

\section{ACKNOWLEDGEMENTS}

The paper has benefited from the constructive suggestions of the associate editor and anonymous reviewers. I would also like to thank Debra Ancona, Lotte Bailyn, Michael Epstein, Debra Gash, Wolf Heydebrand, Margi Olson, Dan Robey, and Marcie Tyre for helpful comments on earlier drafts of this paper. 


\section{REFERENCES}

Aldrich, H. E. (1972), "Technology and Organization Structure: A Reexamination of the Findings of the Aston Group," Administrative Science Quarterly, 17, 26-43.

Anderson, H. W. (1988), "Technological Trajectories, Cultural Values and the Labour Process: The Development of NC Machinery in the Norwegian Shipbuilding Industry," Social Studies of Science, 18, 465-482.

Attewell, P. and J. Rule (1984), "Computing and Organizations: What we know and what we don't know,"Communications of the ACM, 27, 12, 1184-1191.

Barley, S. (1986), "Technology as an Occasion for Structuring: Evidence from Observation of CT Scanners and the Social Order of Radiology Departments," Administrative Science Quarterly, 31, 78-108.

(1990), "The Alignment of Technology and Structure through Roles and Networks" Administrative Science Quarterly, 35, 61-103.

Berger, P. L. and T. Luckmann (1967), The Social Construction of Reality, New York: Anchor Books.

Bernstein, R. J. (1978), The Restructuring of Social and Political Theory, Philadelphia PA: University of Pennsylvania Press.

Bhaskar, R. (1979), The Possibility of Naturalism, Brighton, UK: Harvester Press.

Bijker, W.E. (1987), "The Social Construction of Bakelite: Toward a Ther ty of Invention," in W.E. Bijker, T.P. Hughes and T. Pinch, T. (Eds.), The Social Construction of Technological Systems, Cambridge MA: MIT Press, 159-187.

Bijker, W.E., T.P. Hughes, and T. Pinch, (Eds.) (1987), The Social Construction of Technological Systems, Cambridge MA: MIT Press.

Bjøm-Andersen N., K. Eason and D. Robey (1986), Managing Computer Impact, Norwood NJ: Ablex Publishers.

Blau P., C. McHugh-Falbe, W. McKinley and T. Phelps (1976), "Technology and Organization in Manufacturing," Administrative Science Quarterly, 21, 20-40.

Boland, R. J. and W. Day (1982), "The Phenomenology of Systems Design," Proceedings of the Third International Conference on Information Systems, Ann Arbor MI.

Bostrom, R.P. and J.S. Heinen (1977), "MIS Problems and Failures: A Socio-Technical Perspective," MIS Quarterly, 1, 4, 11-28.

Braverman, H. (1974), Labor and Monopoly Capital: The Degradation of Work in the Twentieth Century, New York: Monthly Review Press.

Burawoy, M. (1979), Manufacturing Consent, Chicago IL: University of Chicago Press. (1985), The Politics of Production, London: Verso Press.

Burrell, G. and G. Morgan (1979), Sociological Paradigms and Organizational Analysis, London: Heinemann. 
Carter, N.M. (1984), "Computerization as a Predominate Technology: Its Influence on the Structure of Newspaper Organizations," Academy of Management Journal, 27, 247-270.

Child, J. (1972), "Organizational Structure, Environment and Performance: The Role of Strategic Choice," Sociology, 6, 1-22.

(1985), "Managerial Strategies, New Technology and the Labour Process," in D. Knights et al. (Eds.), Job Redesign: Critical Perspectives on the Labour Process, Hants UK: Gower, 107-141.

Collins, H.M. (1987), "Expert Systems and the Science of Knowledge," in W.E. Bijker, T.P. Hughes and T. Pinch (Eds.), The Social Construction of Technological Systems, Cambridge MA: MIT Press, 329-348.

Cooley, M. (1980), “Computerization: Taylor's Latest Disguise," Economic and Industrial Democracy, 1, 523-539.

Crozier, M. (1964), The Bureaucratic Phenomenon, Chicago IL: University of Chicago Press.

Davis, L.E. and J.C. Taylor (1986), "Technology, Organization and Job Structure," in R. Dubin (Ed.), Handbook of Work, Organization, and Society, Chicago IL: Rand McNally, 379-419.

Dow, G. K. (1988), "Configurational and Coactivational Views of Organizational Structure," Academy of Management Review, 13, 1, 53-64.

Edwards, R. (1979), Contested Terrain: The Transformation of the Workplace in the Twentieth Century, New York: Basic Books.

Eveland, J.D. (1986), "Diffusion, Technology Transfer, and Implementation," Knowledge, Creation, Diffusion, Utilization, 8, 2, 303-322.

Foster, L.W. and D.M. Flynn (1984), "Management Information Technology: Its Effects on Organizational Form and Function," MIS Quarterly, 229-235.

Garson, B. (1988), The Electronic Sweatshop: How Computers are Transforming the Office of the Future Into the Factory of the Past, New York: Simon and Schuster.

Giddens, A. (1976), New Rules of Sociological Method, New York NY: Basic Books. (1979), Central Problems in Social Theory: Action, Structure and Contradiction in Social Analysis, Berkeley CA: University of Califomia Press.

(1984), The Constitution of Society: Outline of the Theory of Structure, Berkeley CA: University of California Press.

Hartmann, H. I., R.E. Kraut and L.A. Tilly (Eds.) (1986), Computer Chips and Paper Clips: Effects of Technological Change, Washington D.C. National Academy Press.

Heidegger, M. (1962), Being and Time, New York: Harper and Row.

Hickson, D., D.S. Pugh and D. Pheysey (1969), “Operations Technology and Organization Structure: An Empirical Reappraisal," Administrative Science Quarterly, 14, 378-397.

Hiltz, S.R. and K. Johnson (1990), "User Satisfaction with Computer-Mediated Communication Systems," Management Science, 36, 6, 739-764. 
Hirschheim, R., H. Klein and M. Newman (1987), "A Social Action Perspective of Information Systems Development," Proceedings of the Eight International Conference on Information Systems, Pittsburgh PA, 45-56.

Hirschhom, L (1984), Beyond Mechanization: Work and Technology in a Postindustrial Age, Cambridge MA: MTT Press.

Hodson, R. and R.E. Parker (1988), "Work in High-Tech Settings: A Review of the Empirical Literature," Research in the Sociology of Work, 4, 1-30.

Howard, R. (1985), Brave New Workplace, New York: Viking Penguin.

Jarvenpaa, S.L. (1989), "Effects of Task Demands and Graphical Format on Information Processing Strategies," Management Science, 35, 3, 285-303.

Jonscher, C. (1988), "An Economic Study of the Information Technology Revolution," Working Paper 90s:88-053, Sloan School of Management, MIT: Cambridge MA.

Jönsson, S. and A. Grönlund (1988), "Life with a Sub-Contractor: New Technology and Management Accounting," Accounting, Organizations and Society, 13, 5, 512-532.

Kelly, J. E. (1978), “A Re-Appraisal of Socio-Technical Systems Theory,” Human Relations, 31, 12, 1069-1099.

Klein H. and R. Hirschheim (1983), "Issues and Approaches to Appraising Technological Change in the Office: A Consequentialist Perspective," Office: Technology and People, 2, 15-42.

Kling, R. (1980), "Social Analyses of Computing: Theoretical Perspectives in Recent Empirical Research," Computing Surveys, 12, 1, 61-110.

(1987), "Defining the Boundaries of Computing across Complex Organizations," in R. Boland and R. Hirschheim (Eds.) Critical Issues in Information Systems Research, New York NY: Wiley.

and S. Iacono (1984), "Computing as an Occasion for Social Control," Journal of Social Issues, 40, 3, 77-96.

Leavitt, H.J. and T.L. Whistler (1958), "Management in the 1980s," Harvard Business Review, $36,41-48$.

Leifer, R. (1988), "Matching Computer-Based Information Systems with Organizational Structures," MIS Quarterly, 63-73.

Lucas, H. C. Jr. (1975), "Performance and the use of an Information System," Management Science, 20, 908-919.

Mackay, W. E. (1988), "Diversity in the use of Electronic Mail," ACM Transactions on Office Information Systems, 6, 4, 380-397.

Manning, P. K.(1982), “Organizational Work: Structuration of Environments,"British Journal of Sociology, 33, 1, 118-134.

Markus, M. L. (1983), "Power, Politics, and MIS Implementation," Communications of the $A C M, 26,430-444$.

and D. Robey (1988), "Information Technology and Organizational Change: Causal Structure in Theory and Research,"Management Science, 34, 5, 583-598. 
McPhee, R.D. (1985), "Formal Structure and Organizational Communication," in R.D. McPhee and P.K. Tompkins (Eds.), Organizational Communication: Traditional Themes and New Directions, Beverley Hills CA: Sage Publications, 149-178.

Mintzberg, H. (1979), The Structuring of Organizations, Englewood Cliffs NJ: Prentice-Hall.

Mohrman, A.M. and E.E. Lawler In (1984), "A Review of Theory and Research." in F.W. McFarlan (Ed.) The Information Systems Research Challenge, Boston MA: Harvard Business School Press, 135-164.

Mumford, E. (1981), "Participative Systems Design: Structure and Method," Systems, Objectives, Solutions, 1, 5-19.

Newman, M. and D. Rosenberg (1985), "Systems Analysts and the Politics of Organizational Control," International Journal of Management Science, 13, 5, 393-406.

Noble, D.F. (1984), Forces of Production: A Social History of Industrial Automation, New York: Oxford University Press.

Orlikowski, W. J. (1988), "Information Technology and Post-Industrial Organizations: An Exploration of the Computer-Mediation of Production Work," Unpublished Doctoral Dissertation, Stern School of Business, New York University, New York.

Pasmore, W. et al. (1982), "Socio-Technical Systems: A North-American Reflection on Empirical Studies of the Seventies," Human Relations, 35, 12, 1179-1204.

Perrolle, J. A. (1986), "Intellectual Assembly Lines: The Rationalization of Managerial, Profession , and Technical Work," Computers and Social Sciences, 2, 111-121.

Perrow, C. (1967), "A Framework for the Comparative Analysis of Organizations," American Sociological Review, 32, 194-208.

(1983), "The Organizational Context of Human Factors Engineering," Administrative Science Quarterly, 28, 521-541.

Petrigrew, A. M. (1973), “Occupational Specialization as an Emergent Process," Sociological Review, 21, 2, 233-278.

(1985), "Contextualist Research: A Natural Way to Link Theory and Practice," in E.E. Lawler III et al. (Eds.), Doing Research that is Useful for Theory and Practice, San Francisco CA: Jossey-Bass, 222-248.

Pfeffer, J. and H. Leblebici (1977), "Information Technology in Organizational Structure," Pacific Sociological Review, 20, 241-261.

Pinch, T. J. and W.E. Bijker (1984), "The Social Construction of Facts and Artefacts: or How the Sociology of Science and the Sociology of Technology might Benefit Each Other," Social Studies of Science, 14, 399-441.

(1987), "The Social Construction of Facts and Artifacts" in W.E. Bijker, T.P. Hughes and T. Pinch (Eds.), The Social Construction of Technological Systems, Cambridge MA: MIT Press, 17-50.

Piore, M.J. and C.F. Sabel (1984), The Second Industrial Divide, New York: Basic Books. 
Poole, M.S. (1985), "Communication and Organizational Climate: Review, Critique, and a New Perspective," in R.D. McPhee, and P.K. Tompkins (Eds.) Organizational Communication:

Traditional Themes and New Directions, Beverley Hills CA: Sage Publications, 79-108.

and G. DeSanctis (1989), "Use of Group Decision Support Systems as an Appropriation Process," Proceedings of the Hawaii International Conference on Information Systems, Hawaii, 149-157.

and G. DeSanctis (1990), "Understanding the use of Group Decision Support Systems: The Theory of Adaptive Structuration," in J. Fulk and C. Steinfield (Eds.) Organizations and Communication Technology, Newbury Park CA: Sage Publications, 173-193.

and A. H. Van de Ven (1989), "Using Paradox to Build Management and Organization Theories," Academy of Management Review, 14, 4, 562-578.

Powell, W. W. (1987), "Review Essay: Explaining Technological Change," American Journal of Sociology, 93, 1, 185-197.

Ranson S., B. Hinings and R. Greenwood (1980), "The Structuring of Organizational Structures," Administrative Science Quarterly, 25, 1-17.

Riley, P. (1983), “A Structurationist Account of Political Culture," Administrative Science Quarterly, 28, 347-414.

Roberts, J. and R. Scapens (1985), “Accounting Systems and Systems of Accountability: Understanding Accounting Practices in their Organizational Context," Accounting, Organizations, and Society, 10, 4, 443-456.

Robey, D. (1981), “Computer Information Systems and Organization Structure," Communications of the $A C M, 24,10,679-687$.

K.A. Vaverek and C.S. Saunders (1989), "Social Structure and Electronic Communication: A Study of Computer Conferencing," Paper presented at the Hawaii International Conference on Information Systems, Hawaii.

Rousseau, D.M. (1985), "Issues of Level in Organizational Research: Multi-level and Cross-level Perspectives," in Research in Organizational Behavior 7, Greenwich CT: JAI Press, 1-37.

Sabel, C.F. (1982), Work and Politics, New York: Cambridge University Press.

Scott, W.R. (1981), Organizations: Rational, Natural, and Open Systems, Englewood Cliffs NJ: Prentice-Hall.

Siegel. J., V. Dubrovsky, S. Kiesler and T.W. McGuire (1986), "Group Processes in ComputerMediated Communication," Organizational Behavior and Human Decision Processes, 37, $157-187$.

Shaiken, H. (1985), Work Transformed: Automation and Labor in the Computer Age, New York NY: Holt, Rinehart and Winston.

Shepard, J. (1977), "Technology, Alienation, and Job Satisfaction," Annual Review of Sociology, 3, 1-21.

Smith, C. W. (1983), "A Case Study of Stucturation: The Pure-Bred Beef Business," Journal for the Theory of Social Behaviour, 13, 3-18. 
Spybey, T. (1984), "Traditional and Professional Frames of Meaning in Management," Sociology, $18,4,550-562$.

Suchman, L. and Wynn, E. (1984), "Procedures and Problems in the Office," Office: Technology and People, 2, 133-154.

Thompson, J. D. (1967), Organizations in Action, New York: McGraw-Hill.

Trist, E.L., G.W. Higgin, H. Murray and A.B. Pollock (1963), Organizational Choice, London UK: Tavistock.

Tyre, M.J. (1988), "Managing the Introduction of New Process Technology: A Study of Organizational Problem Solving at the Plant Level," Unpublished Doctoral Dissertation, Harvard Business School, Boston MA.

Weick, K. (1979), The Social Psychology of Organizing, Reading MA: Addison-Wesley.

Willmott, H. (1981), "The Structuring of Organizational Structures: A Note," Administrative Science Quarterly, 26, 470-474.

Studies, 24, 3, 249-270.

(1987), "Studying Managerial Work: A Critique and a Proposal," Journal of Management.

Woodward, J. (1958), Management and Technology, London: H.M.S.O. (1965), Industrial Organization: Theory and Practice, London: Oxford University Press.

V" olgar, S. (1985), "Why not a Sociology of Machines? The Case of Sociology and Artificial I...elligence," Sociology, 19, 557-572.

Wynne, B. (1988), "Unruly Technology: Practical Rules, Impractical Discourses and Public Understanding," Social Studies of Science, 18, 147-167.

Zuboff, S. (1988), In the Age of the Smart Machine, New York: Basic Books. 